\title{
Analisis Numerik Pengaruh Sudut Sudu Pengarah Difuser Jet Swirling dan Grille Terhadap Distribusi Sifat-Sifat Termodinamika Udara dalam Ruang Terkondisi
}

\author{
Arwizet Karudin ${ }^{*}$ \\ ${ }^{1}$ Jurusan Teknik Mesin, Fakultas Teknik, Universitas Negeri Padang \\ "e-mail: arwizet@ft.unp.ac.id
}

\begin{abstract}
Abstrak - Sistem pendistribusian udara mempunyai tugas utama yaitu mengalirkan udara dingin dan bersih dalam jumlah yang tepat ke dalam ruangan yang dikondisikan. Salah satu alat dari sistem pendistribusian udara adalah difuser. Difuser yang banyak digunakan dalam sistem pengkondisian udara adalah jet swirling dan grille. Penelitian ini bertujuan untuk mengetahui pengaruh penggunaan sudut sudu difuser terhadap distribusi temperatur dan kecepatan udara dalam ruang yang dikondisikan. Metode pada penelitian ini adalah melakukan proses simulasi numerik dengan bantuan software Computational Fluid Dynamic Fluent Release 4.2 terhadap distribusi temperatur dan kecepatan udara keluar dari difuser jet swirling dan difuser grille dengan kecepatan keluar difuser diasumsikan sama. Sudut sudu pengarah dari kedua difuser ditetapkan $\mathbf{4 5}^{\circ}$ dan $60^{\circ}$ dengan pemodelan turbulensi $k-\varepsilon$ standard. Hasil simulasi memperlihatkan bahwa untuk difuser jet swirling sudut sudu $\mathbf{4 5}^{\circ}$, distribusi temperatur yang dihasilkan lebih rendah dan dan kecepatan udara lebih tinggi jika dibanding sudut sudu $60^{\circ}$. Untuk difuser grille terjadi sebaliknya dimana untuk sudut sudu $60^{\circ}$ distribusi temperatur yang dihasilkan juga lebih lebih rendah dan kecepatan udara lebih lebih besar jika dibandingkan dengan sudut sudu $60^{\circ}$. Dari hasil simulasi dapat disimpulkan bahwa difuser jet swirling dengan sudut sudu $45^{\circ}$ dapat menghasil distribusi temperatur lebih rendah dibanding dengan sudut sudu $60^{\circ}$. Untuk difuser grille sudut sudu $60^{\circ}$ dapat menghasil distribusi temperatur lebih rendah dibanding dengan sudut sudu $\mathbf{4 5}^{\circ}$.
\end{abstract}

Kata Kunci : Jet Swirling, Grille, Computational Fluid Dynamic, Fluent, Simulasi, Komputer.

\begin{abstract}
The air distribution system has the main task of delivering the right amount of cold and clean into the conditioned room. One of the tools of the air distribution system was the diffuser. Diffusers which are widely used in air conditioning systems were swirling jet and grille. This study aims to determine the effect of the use of diffuser blade angle on distribution of the temperature and air velocity in conditioned room. The method in this study was to carry out a numerical simulation process with the help of Computational Fluid Dynamic Fluent Release 4.2 software on temperature distribution and air velocity of the jet swirling diffuser and grille diffuser with the diffuser exit velocity assumed to be the same. The directive blade angles of the two diffuser were set at 450 and 600 with $k-\varepsilon$ standard turbulence modeling. The simulation results show that for a $45^{\circ}$ angle swirling jet diffuser, the resulting temperature distribution was lower and the air velocity is higher than the $60^{\circ}$ blade angle. For the grille diffuser the opposite occurs where for the $60^{\circ}$ blade angle the resulting temperature distribution was also lower and the air velocity was greater when compared to the $60^{\circ}$ blade angle. From the simulation results it can be concluded that the jet swirling diffuser with a $45^{\circ}$ blade angle can produce a lower temperature distribution compared to the $60^{\circ}$ blade angle. For a $60^{\circ}$ blade angle diffuser grille can produce a lower temperature distribution compared to a $45^{\circ}$ blade angle.
\end{abstract}

Keywords : Swirling Jet, Grille. Computational Fluid Dynamic, Fluent, Simulation, Computer

This is an open access article distributed under the Creative Commons 4.0 Attribution License 


\section{Pendahuluan}

Sistem distribusi udara adalah salah satu faktor yang krusial dari sistem pengkondisian udara[1].[2] Sistem ini mempunyai tugas utama yaitu mengalirkan udara dingin dan bersih dalam jumlah yang tepat ke dalam ruangan. Udara dingin dan bersih tersebut dialirkan melalui alat mekanis yang disebut dengan difuser. Difuser berfungsi untuk mengalirkan udara terkondisi ke dalam ruangan. Difuser berfungsi untuk membuat turbulensi aliran udara agar proses pencampuran udara berlangsung dengan baik.

Ada beberapa fungsi dasar yang harus dipenuhi oleh difuser sebagai bagian dari sistem distribusi udara. Difuser harus mampu mengatasi panas yang dicetuskan oleh sumber panas baik dari luar dan dalam ruangan. Selain itu difuser ini juga disyaratkan harus mampu menjaga variasi temperatur udara ruangan yang dikondisikan [3].

Pola distribusi sifat-sifat termodinamika udara seperti temperatur, kelembaban, dan kecepatan dalam ruangan adalah hasil interaksi antara gaya inersia, gaya tekan, gaya gesek dan gaya apung (bouyancy)[4]. Temperatur dan kecepatan udara adalah dua faktor yang juga perlu diperhatikan dalam sistem distribusi udara. Jika kecepatan udara terlalu tinggi akan mengakibat- kan pelepasan kalor dari permukaan tubuh lebih banyak, sehingga menyebabkan terjadinya fenomena draft, orang akan kedinginan. Sebaliknya jika tidak ada aliran udara maka akan terjadi fenomena stuffiness dimana kalor yang dilepaskan tubuh ke lingkungan terlalu sedikit, orang akan kepanasan[4].

Nilai kecepatan udara yang optimum sangat tergantung kepada kegiatan dari penghuninya. Berikut kecepatan udara yang direkomendasikan untuk berbagai kegiatan[5]:

Tabel 1. Kecepatan Udara yang Direkomendasikan dalam Ruangan

\begin{tabular}{|c|c|c|}
\hline $\begin{array}{c}\text { Kecepatan } \\
\text { udara } \\
(\mathbf{m} / \mathbf{s})\end{array}$ & Reaksi & Rekomendasi \\
\hline $0-0,08$ & $\begin{array}{c}\text { Keluhan udara diam } \\
\text { Ideal dan favorit }\end{array}$ & $\begin{array}{c}\text { Tidak ada } \\
\text { Semua ruang } \\
\text { hunian }\end{array}$ \\
$0,13-0,25$ & $\begin{array}{c}\text { Cukup ideal dan } 0,25 \mathrm{~m} / \mathrm{s} \\
\text { batas maksimum untuk } \\
\text { orang duduk } \\
\text { hunian }\end{array}$ \\
0,33 & $\begin{array}{c}\text { Tidak favorit karena kertas } \\
\text { akan berterbangan } \\
\text { Batas maksimum yang baik } \\
\text { untuk orang bergerak pelan }\end{array}$ & $\begin{array}{c}\text { Tidak ada } \\
\text { Pasar swalayan, } \\
\text { Bank, Toko }\end{array}$ \\
$0,4-1,5$ & $\begin{array}{c}\text { Baik untuk instalasi peng- } \\
\text { kondisian udara di bebe- } \\
\text { rapa industri }\end{array}$ & $\begin{array}{c}\text { Pabrik yang butuh } \\
\text { pengkondisian } \\
\text { cepat }\end{array}$ \\
\hline
\end{tabular}

[6] Pola aliran udara dalam suatu ruangan juga sangat menentukan distribusi temperatur dan kecepatan udara dalam suatu ruangan. Pola aliran udara yang hanya terfokus pada suatu titik saja, maka distribusi temperatur dan kecepatan udara terkonsentrasi hanya disekitar titik itu pula, sebaliknya jika pola aliran udara sifatnya menyebar maka kecepatan udara dalam suatu ruang akan lebih merata. Untuk mendapatkan pola aliran udara yang lebih menyebar sangat ditentukan oleh jenis difuser udara yang digunakan dalam suatu ruang. Beberapa jenis difuser udara yang biasa digunakan yaitu jet swirling, ceiling, dan grille[7].

Besar kecilnya temperatur dan kecepatan udara dalam ruang yang dikondisikan selain dipengaruhi oleh kecepetan udara masuk, juga dipengaruhi oleh jenis difuser dan sudut difuser. Sudut difuser yang biasa digunakan dalam sistem pengkondisian udara adalah $30^{\circ}, 45^{\circ}$ dan $60^{\circ}$. Secara teoritik semakin besar sudut sudu difuser maka sebaran udara akan lebih luas dan lebih merata.

Berdasarkan bentuk konstruksi dan lokasi penempatannya diffuser dikelompokkan menjadi difuser jet swirling, grille, ceiling universal, perforated ceiling panels dan sebagainya[13].

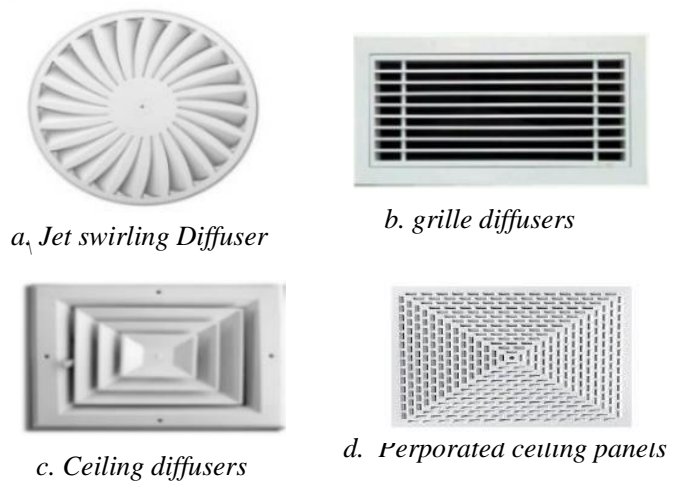

Gambar 1. Bentuk-bentuk Difuser yang Dapat Digunakan dalam Teknik Pengkondisian Udara

Pemilihan dan penempatan difuser harus dirancang sedimikan rupa agar tercapai kondisi ruangan sesuai dengan perencanaan tanpa mengabaikan pertimbangan faktor ekonomi. Optimalisasi dalam difuser dapat dicapai dengan memperhatikan prinsip-prinsip[1]:

a. Karakteristik semburan udara bebas.

b. Karakteristik kecepatan pada jalan masuk udara.

c. Gaya apung (bouyancy).

d. Pembelokan arah (deflection). 
Unjuk kerja difuser yang digunakan untuk pengkondisian udara ditentukan oleh parameter berikut :

\section{A. Semburan (blow/throw)}

Semburan adalah jarak horizontal terjauh yang mampu dicapai oleh udara keluar dari difuser. Jarak ini diukur dari difuser sampai ke suatu titik dimana kecepatan aliran udara itu sangat kecil, tetapi masih dapat dirasakan oleh alat ukur dengan kecermatan $0,1 \mathrm{~m} /$ detik. Besarnya semburan akan sebanding dengan kecepatan udara primer yang keluar dari difuser dan tidak dipengaruhi oleh beda temperatur antara udara suplai dengan udara dalam ruangan.

\section{B.Jangkauan (drop/rise)}

Jangkauan adalah jarak vertikal yang mampu dicapai oleh udara dari saat meninggalkan difuser sampai ke suatu titik dimana kecepatan udara menjadi sangat kecil, tetapi masih dapat dirasakan oleh alat ukur dengan kecermatan $0,1 \mathrm{~m} /$ detik. Jika udara dingin yang disemburkan dari difuser, maka aliran udara akan cendrung turun (drop) ke daerah hunian. Hal ini disebabkan oleh pengaruh perbedaan massa jenis udara primer dengan udara sekunder. Sebaliknya apabila yang disemburkan adalah udara panas maka arah aliran cendrung naik ke atas (rise). Jika temperatur udara suplai hampir sama dengan udara dalam ruangan maka aliran cendrung tidak naik atau turun.

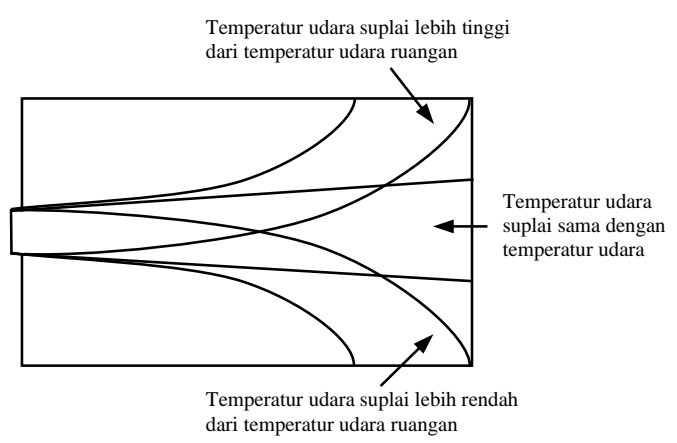

Gambar 2. Arah Aliran Udara untuk Beberapa Kondisi Temperatur Udara Suplai[7]

\section{Induksi (induction)}

Induksi adalah udara ruangan yang ikut mengalir akibat adanya kecepatan dari aliran udara yang keluar dari difuser. Udara yang keluar dari difuser disebut udara primer, sedangkan udara yang ikut terbawa aliran udara primer disebut udara sekunder. Campuran dari udara primer dan udara sekunder disebut udara total. Induksi dinyatakan dalam bentuk persamaan momentum berikut[10]:

$$
\mathrm{M}_{1} \mathrm{~V}_{1}+\mathrm{M}_{2} \mathrm{~V}_{2}=\left(\mathrm{M}_{1}+\mathrm{M}_{2}\right) \mathrm{V}_{3}
$$

Rasio induksi (R) didefinisikan sebagai perbandingan antara laju aliran udara total dan udara primer[14] :

$$
\mathrm{R}=\frac{\text { debit udara total }}{\text { debit udara primer }}
$$

\section{Penyebaran (spread)}

Penyebaran adalah sudut penyebaran dari aliran udara setelah meninggalkan difuser. Penyebaran horizontal (horinzontal spread) mempunyai penyebaran pada bidang horizontal. Sedangkan penyebaran vertikal mempunyai penyebaran pada bidang vertikal.

Jenis difuser berdasarkan bentuk sudu pengarahnya dapat diklasifikasikan sebagai berikut[11]:

a. Difuser sudu pengarah sejajar (straight vanes)

b. Difuser sudu pengarah menguncup (converging vanes)

c. Difuser sudu pengarah menyebar (diverging vanes)

Difuser dengan sudu pengarah sejajar menghasilkan penyebaran (spread) dengan sudut sekitar $19^{\circ}$. Difuser dengan sudu pengarah menguncup menghasilkan penyebaran hampir sama dengan difuser sudu pengarah sejajar yaitu sekitar $19^{\circ}$, tetapi mempunyai jarak semburan sekitar 15 persen lebih jauh dari pada difuser sudu pengarah sejajar.
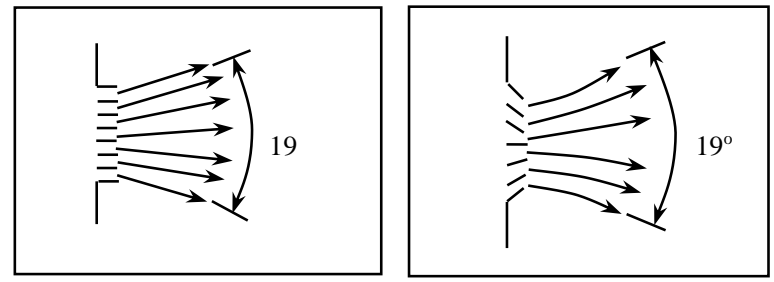

Gambar 3. Penyebaran Udara pada Difuser Sudu Pengarah Sejajar dan Menguncup[11]

Difuser dengan sudu pengarah menyebar mempunyai penyebaran dengan sudut yang lebih besar jika dibandingkan dengan difuser jenis lainnya. Pada sudut sudu pengarah $45^{\circ}$ atau lebih akan menghasilkan sudut penyebaran sekitar $60^{\circ}$, tetapi jarak 
semburannya berkurang sekitar 50 persen[11]. Sedangkan untuk sudut sudu pengarah $30^{\circ}$, jarak semburannya akan lebih jauh tetapi masih lebih pendek jika dibandingkan dengan difuser pengarah sejajar.

Luas penampang saluran masuk difuser sudu pengarah menyebar pada umumnya lebih kecil dari pada difuser jenis lainnya, sehingga jumlah udara keluarannya akan lebih sedikit dengan penurunan tekanan besar pada debit yang sama. Untuk mempertahankan debit udara masukan yang sama, kendala ini diatasi dengan memakai difuser sudu pengarah sejajar dengan sudut kemiringan tertentu seperti diperlihatkan pada gambar $4^{[10]}$.
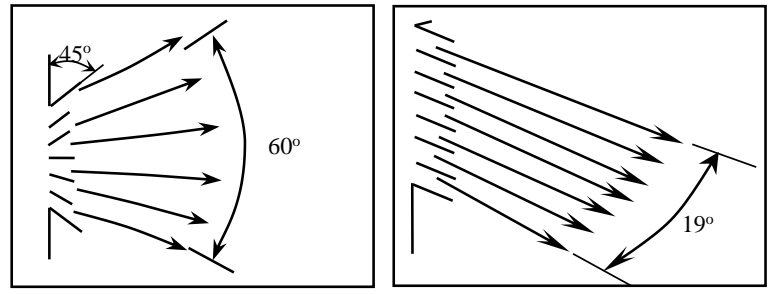

Gambar 4. Penyebaran Udara pada Difuser Sudu Pengarah Menyebar dan Sejajar dengan Sudut Tertentu[11]

\section{MetodA}

Metode penelitian di awali oleh pemilihan model turbuensi, penggunaan model dikretisasi, pemodelan dan membuat model simulasi ruang yang dikondisikan.

\section{A. Model Turbulensi}

Program Computational Fluid Dynamic Fluent 4.2 menyediakan beberapa model untuk aliran turbulen. Proses simulasi numerik pada penelitian ini model tubulensi yang digunakan adalah model k- $\varepsilon$ standart[15].

Pemodelan k- $\varepsilon$ standard menggunakan model semi-empirik yang didasarkan atas model persamaan transport untuk energi kinetik turbulen (k) dan laju disipasi turbulen ( $\varepsilon$ ) dengan memanfaatkan hipotesa dari Boussinesq. Pada penurunan pemodelan ini, kita mengasumsikan bahwa aliran sepenuhnya turbulen dan efek viskositasnya diabaikan. Pemodelan jenis ini cocok untuk aliran turbulen penuh.
Persamaan transportnya model turbulensi k- $\varepsilon$ standart adalah[16]:

$\rho \frac{\mathrm{Dk}}{\mathrm{Dt}}=\frac{\partial}{\partial \mathrm{x}_{\mathrm{i}}}\left[\left(\mu+\frac{\mu_{\mathrm{t}}}{\sigma}\right) \frac{\partial \mathrm{k}}{\partial \mathrm{x}_{\mathrm{i}}}\right]+\mathrm{G}_{\mathrm{k}}+\mathrm{G}_{\mathrm{b}}-\rho \varepsilon-\mathrm{Y}_{\mathrm{M}}$

dan

$\rho \frac{\mathrm{D} \varepsilon}{\mathrm{Dt}}=\frac{\partial}{\partial \mathrm{x}_{\mathrm{i}}}\left[\left(\mu+\frac{\mu_{\mathrm{t}}}{\sigma_{\mathrm{k}}}\right) \frac{\partial \varepsilon}{\partial \mathrm{x}_{\mathrm{i}}}\right]+\mathrm{C}_{1 \varepsilon} \frac{\varepsilon}{\mathrm{k}}\left(\mathrm{G}_{\mathrm{k}}+\mathrm{C}_{3 \varepsilon} \mathrm{G}_{\mathrm{b}}\right)-\mathrm{C}_{2 \varepsilon} \rho \frac{\varepsilon^{2}}{\mathrm{k}} \ldots$

$\mathrm{Y}_{\mathrm{M}}$ menyatakan kontribusi dari fluktuasi dilatasi pada turbulen kompresibel pada seluruh laju disipasi. $\mathrm{C}_{1 \varepsilon}, \mathrm{C}_{2 \varepsilon}$ dan $\mathrm{C}_{3 \varepsilon}$ adalah konstanta masing-masing nilainya adalah 1,$44 ; 1,92$; dan 0,09 . $\sigma_{\mathrm{k}}$ dan $\sigma_{\varepsilon}$ adalah bilangan Prandtl turbulen untuk $\mathrm{k}$ dan $\varepsilon$ dengan nilainya masing-masing 1 dan 1,3. Angka-angka ini diperoleh dari fasilitas yang ada.

\section{B. Metode Diskretisasi}

Dalam menganalisis persamaan-persamaan yang membangun aliran fluida. Fluent menggunakan teknik khusus berdasarkan volume kontrol guna mengubah persamaan tersebut menjadi persamaan aljabar yang dapat dicari solusinya secara numerik. Teknik ini dilakukan dengan cara mengintegrasikan persamaan di tiap volume kontrol sehingga diperoleh persamaan diskret yang menggambarkan variabel-variabel aliran fluida[17].

Secara umum, proses fisik yang memenuhi prinsip konservasi dapat dinyatakan dalam persamaan diferensial berikut:

$\frac{\partial}{\partial t}(\rho \phi)+\operatorname{div}(\rho u \phi)=\operatorname{div}(\operatorname{\Gamma grad} \phi)+S$

Dalam Fluent persamaan diferensial tersebut akan ditransformasikan menjadi persamaan linier dengan menggunakan metode volume kontrol. Metode ini dimulai dengan membagi-bagi domain perhitungan menjadi daerah-daerah kecil (volume kontrol) dan menjadikan titik tengahnya sebagai nodal mewakili sifat-sifat daerah tersebut.

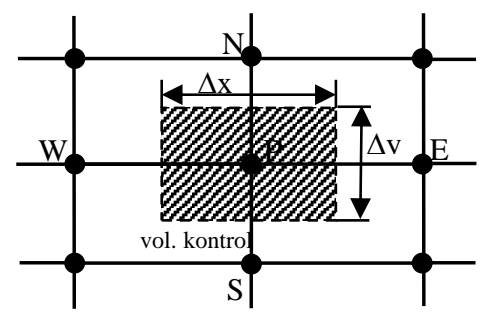

Gambar 5. Volume Kontrol dalam Bentuk 2-Dimensi. 
Dengan mengintegrasikan persamaan konservasi pada volume kontrol, akan diperoleh suatu persamaan diskretisasi dalam bentuk:

$$
a_{p} \phi_{p}=\sum_{n b} a_{n b} \phi_{n b}+b
$$

dimana $\phi$ adalah suatu besaran yang tergantung pada persamaan yang akan diselesaikan.

Tiap-tiap volume kontrol dalam domain perhitungan dapat dituliskan dengan persamaan (5). Banyaknya persamaan aljabar linier seperti pada persamaan (6) yang dibangun, sangat tergantung pada jumlah volume kontrol yang dibuat dan jumlah persamaan-persamaan matematika dari proses-proses fisik yang ada.

Dalam proses iterasi, perubahan nilai $\phi$ perlu dikontrol sehingga diperoleh penurunan residu yang stabil dengan konvergensi yang relatif cepat. Kontrol dilakukan dengan menggunakan faktor under relaksasi $(\alpha)$, dimana nilai baru dari $\phi$ pada setiap iterasi dapat ditulis sebagai:

$$
\phi_{\text {baru }}=\phi_{\text {lama }}+\alpha\left(\phi_{\text {hitungan }}-\phi_{\text {lama }}\right)
$$

Pemilihan nilai $\alpha$ yang tepat akan menghasilkan proses iterasi yang baik. Sebaliknya pemilihan nilai $\alpha$ yang tidak tepat akan mengahasilkan proses iterasi yang kurang baik. Proses iterasi akan berhenti jika residu memenuhi kriteria konvergen.

\section{Residual $=\phi_{n+1}-\phi_{n} \leq$ kriteria konvergen $\quad \ldots$ (8)}

Umumnya kriteria konvergen akan dicapai bila angka residual yang didapat mencapai orde $10^{-3}$ untuk kecepatan dan kontinuitas.

\section{Pemodelan dan Data Simulasi \\ a. Pemodelan}

Pemodelan aliran udara dalam ruangan dibagi dalam dua tahapan yaitu tahapan proses di Gambit dan di Fuent.

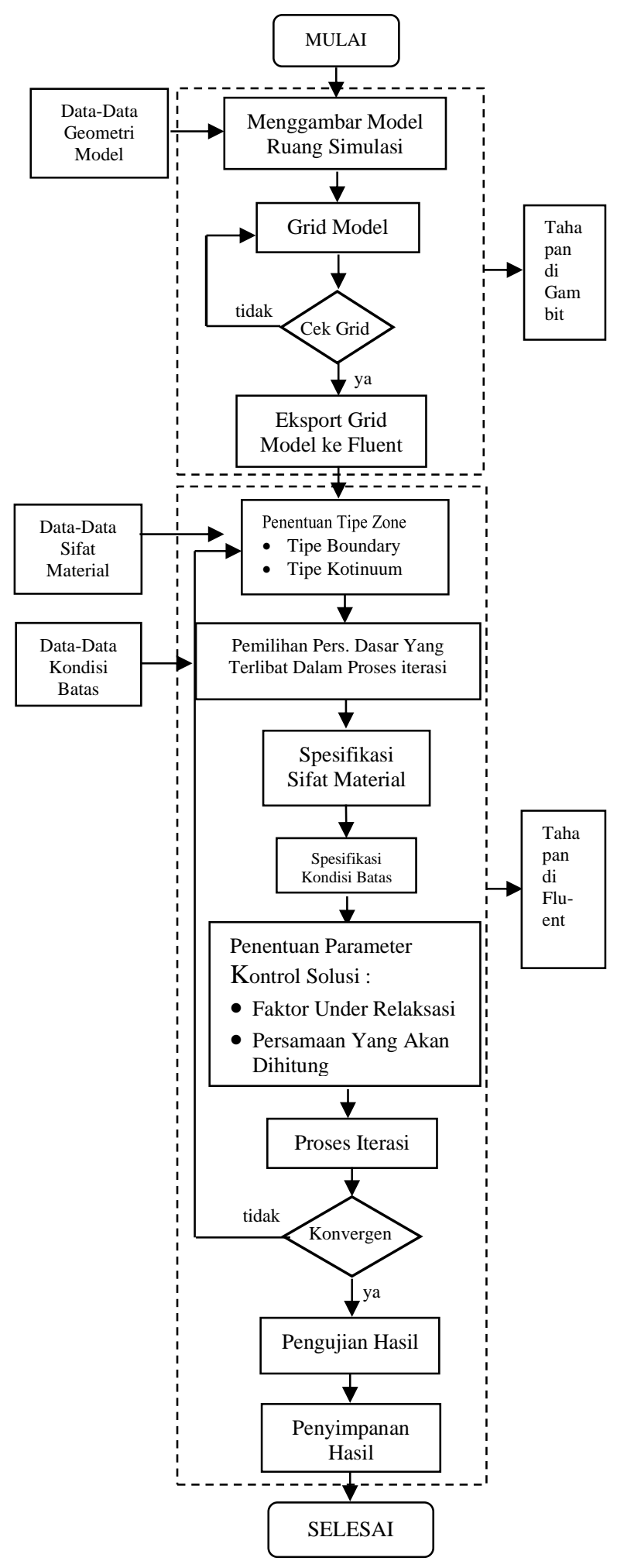

Gambar 6. Diagram Alir Pemodelan Simulasi

Penggambaran geometri ruangan untuk keperluan pemodelan didasarkan pada ukuran gambar teknik dari ruangan yang sebenarnya. Selanjutnya dilakukan proses meshing. Gambar geometri ruangan yang akan disimulasikan dan 
hasil diskretisasinya dapat dilihat pada gambar 7 dan 8 .
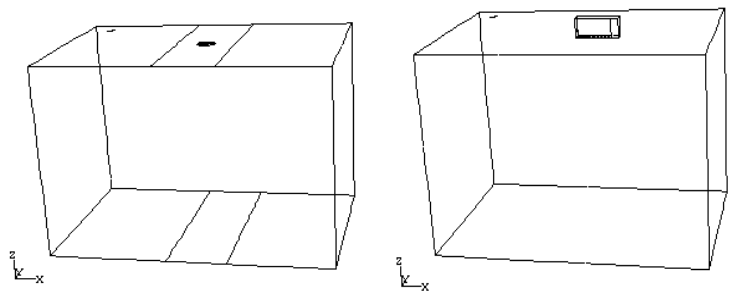

Gambar 7. Model Ruangan yang Disimulasikan untuk Difuser Jet Swirling dan Grille

Setelah model ruang yang akan disimulasikan dibuat, dilanjtkan dengan proses meshing. Hasil proses meshing terlihat pada gambar 8 .
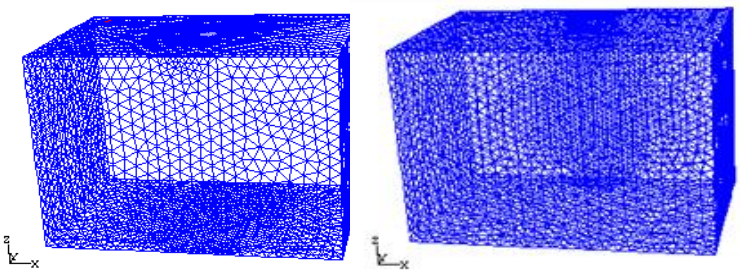

Gambar 8. Diskretisasi Model Ruangan untuk Difuser Jet Swirling dan Grille

\section{b. Data Simulasi}

Sebelum melakukan penyelesaian persamaan (iterasi) pada Fluent diperlukan data-data input seperti berikut:

a) Kondisi batas pada inlet yaitu: laju aliran massa udara $(\mathrm{kg} / \mathrm{s})$ dan temperatur udara masuk $\left({ }^{\circ} \mathrm{C}\right)$.

b) Kondisi batas pada outlet adalah: tekanan udara keluar $(\mathrm{Pa})$.

c) Kondisi batas pada dinding (wall) adalah: massa jenis $\left(\mathrm{kg} / \mathrm{m}^{3}\right)$, panas jenis $(\mathrm{J} / \mathrm{kg} . \mathrm{K})$, konduktivitas termal (W/m.K) dan fluks panas $\left(\mathrm{W} / \mathrm{m}^{2}\right)$.

d) Sifat-sifat fluida yaitu: massa jenis $\left(\mathrm{kg} / \mathrm{m}^{3}\right)$, panas jenis (J/kg.K) dan viskositas $(\mathrm{kg} / \mathrm{ms})$

Pada penelitian ini ruangan yang disimulasikan diasumsikan dalam kondisi kosong. Beban pendinginan hanya berasal dari luar ruangan melalui dinding partisi. Beban pendinginan ruang simulasi pada Fluent di masukan dalam kondisi batas "wall" dengan besar masing-masing seperti terlihat pada tabel 2 .
Tabel 2. Masukan Besaran Beban Pendinginan pada Fluent.

\begin{tabular}{|c|c|c|c|c|}
\hline No & Jenis beban & $\begin{array}{c}\text { Lokasi } \\
\text { permukaan }\end{array}$ & $\begin{array}{c}\text { Material } \\
\text { dinding }\end{array}$ & $\begin{array}{c}\text { Jumlah } \\
\text { (Watt) }\end{array}$ \\
\hline 1 & $\begin{array}{c}\text { Konduksi } \\
\text { dinding }\end{array}$ & Utara & Brick & 87,7443 \\
\hline 2 & $\begin{array}{c}\text { Konduksi } \\
\text { dinding }\end{array}$ & Selatan & Plywood & 136,0462 \\
\hline 3 & $\begin{array}{l}\text { Konduksi } \\
\text { dinding }\end{array}$ & Barat & Plywood & 49,7925 \\
\hline 4 & $\begin{array}{l}\text { Konduksi } \\
\text { dinding }\end{array}$ & Timur & Brick & 73,1702 \\
\hline 5 & $\begin{array}{l}\text { Konduksi } \\
\text { dinding }\end{array}$ & $\begin{array}{c}\text { Lantai } \\
\text { (bawah) }\end{array}$ & Concrete & 128,9009 \\
\hline 6 & $\begin{array}{l}\text { Konduksi } \\
\text { dinding }\end{array}$ & Plafon (atas) & Plywood & 119,9470 \\
\hline
\end{tabular}

\section{a) Data Simulasi Untuk Difuser Jet Swirling}

Data simulasi untuk difuser jet swirling berupa laju aliran massa udara keluar dari difuser, temperatur dan arah aliran udara. Difuser jet swirling yang disimulasikan dibedakan atas dua model berdasarkan variasi sudut sudu pengarahnya yaitu $45^{\circ}$ dan $60^{\circ}$ terhadap sumbu aksial (sumbu Z).

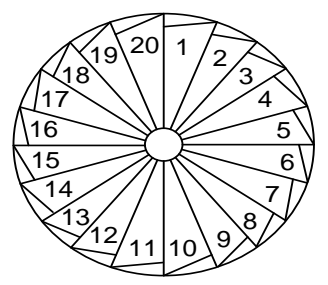

\section{Gambar 9. Difuser Jet Swirling}

Difuser jet swirling sudut sudu pengarah $45^{\circ}$

- Total laju aliran massa udara catu $=0,122739 \mathrm{~kg} / \mathrm{s}$

- Jumlah sudu pada difuser catu $=20$

- Temperatur udara catu $\quad=17^{\circ} \mathrm{C}$

- Laju aliran massa udara tiap difuser catu = $0,006137 \mathrm{~kg} / \mathrm{s}$

- Diameter diffuser $=0,30 \mathrm{~m}$

Difuser jet swirling sudut sudu pengarah $60^{\circ}$

- Total laju aliran massa udara catu $=0,126600 \mathrm{~kg} / \mathrm{s}$

- Jumlah sudu pada difuser catu $=20$

- Temperatur udara catu $\quad=17^{\circ} \mathrm{C}$

- Laju aliran massa udara tiap difuser catu $=0,006330 \mathrm{~kg} / \mathrm{s}$

- Diameter difuser $=0,30 \mathrm{~m}$ 
Data lain yang perlu di masukan ke dalam Fluent untuk proses pensimulasian adalah:

(a) Data Material

Tabel 3. Data Material

\begin{tabular}{|c|l|c|c|c|}
\hline No & $\begin{array}{c}\text { Jenis } \\
\text { material }\end{array}$ & $\begin{array}{c}\text { Massa } \\
\text { jenis } \\
\left(\mathrm{kg} / \mathrm{m}^{3}\right)\end{array}$ & $\begin{array}{c}\text { Panas } \\
\text { jenis } \\
(\mathrm{J} / \mathrm{kg} . \mathrm{K})\end{array}$ & $\begin{array}{c}\text { Konduk- } \\
\text { tivitas } \\
\text { termal } \\
(\mathrm{W} / \mathrm{m} . \mathrm{K})\end{array}$ \\
\hline 1 & Brick & 1920 & 835 & 0,72 \\
\hline 2 & Glass & 2500 & 750 & 1,40 \\
\hline 3 & Plywood & 545 & 1215 & 0,12 \\
\hline 4 & Concrete & 12300 & 880 & 1,4 \\
\hline 5 & $\begin{array}{l}\text { Fiber } \\
\text { glass }\end{array}$ & 105 & 795 & 0,036 \\
\hline 6 & Udara & $\begin{array}{c}\text { Gas } \\
\text { ideal }\end{array}$ & 1006,43 & 0,0242 \\
\hline
\end{tabular}

\section{(b) Data Kondisi Batas}

Data kondisi batas untuk difuser jet swirling dengan sudut sudu pengarah $45^{\circ}$ dan $60^{\circ}$ terhadap sumbu aksial (sumbu Z), terdiri atas:

Tabel 4. Data Kondisi Batas

\begin{tabular}{|c|c|c|c|c|c|}
\hline No & Jenis & $\begin{array}{c}\text { Kondisi } \\
\text { Batas }\end{array}$ & \multicolumn{3}{|c|}{ Nilai Fluks Panas (W/m.K) } \\
\hline 1 & $\begin{array}{c}\text { Dinding } \\
\text { Utara, } \\
\text { selatan, } \\
\text { barat } \\
\text { dan } \\
\text { timur }\end{array}$ & Wall & \multicolumn{3}{|c|}{5,$597 ; 8,682 ; 4,715 ; 6.928$} \\
\hline 2 & Lantai & Wall & \multicolumn{3}{|c|}{8,480} \\
\hline 3 & Plafon & Wall & \multicolumn{3}{|c|}{7,928} \\
\hline \multirow[t]{2}{*}{4} & \multirow[t]{2}{*}{ Inlet } & \multirow{2}{*}{$\begin{array}{l}\text { Nomor } \\
\text { sudu } \\
\text { difuser }\end{array}$} & \multicolumn{3}{|c|}{$\begin{array}{c}\text { Laju aliran massa udara difuser jet } \\
\text { swirling sudut sudu } 45^{\circ} \text { terhadap } \\
\text { sumbu } Z(\mathrm{~kg} / \mathrm{s})\end{array}$} \\
\hline & & & $\dot{\mathrm{m}}_{x}$ & $\dot{\mathrm{m}}_{\mathrm{y}}$ & $\dot{\mathrm{m}}_{\mathrm{z}}$ \\
\hline & & 1 & $\begin{array}{c}4,3390 . \\
10^{-3}\end{array}$ & 0 & $\begin{array}{c}-4,339 \\
10^{-3}\end{array}$ \\
\hline & & 2 & $\begin{array}{c}4,1266 . \\
10^{-3}\end{array}$ & $\begin{array}{c}-1,3408 \\
10^{-3}\end{array}$ & $\begin{array}{c}-4,339 \\
10^{-3}\end{array}$ \\
\hline & & 3 & $\begin{array}{c}3,5100 . \\
10^{-3}\end{array}$ & $\begin{array}{c}-2,5500 \\
10^{-3} \\
\end{array}$ & $\begin{array}{c}-4,339 \\
10^{-3} \\
\end{array}$ \\
\hline & & 4 & $\begin{array}{c}2,5500 . \\
10^{-3}\end{array}$ & $\begin{array}{c}-3,5100 \\
10^{-3}\end{array}$ & $\begin{array}{c}-4,339 \\
10^{-3}\end{array}$ \\
\hline & & 5 & $\begin{array}{c}1,3408 \\
10^{-3} \\
\end{array}$ & $\begin{array}{c}4,1266 . \\
10^{-3} \\
\end{array}$ & $\begin{array}{c}-4,339 \\
10^{-3} \\
\end{array}$ \\
\hline & & $\ldots(\mathrm{dst})$ & $\ldots$ & $\ldots$ & $\ldots$ \\
\hline & & 20 & $\begin{array}{c}4,1266 . \\
10^{-3}\end{array}$ & $\begin{array}{c}1,3408 \\
10^{-3}\end{array}$ & $\begin{array}{c}-4,339 \\
10^{-3}\end{array}$ \\
\hline \multirow[t]{2}{*}{5} & \multirow[t]{2}{*}{ Inlet } & \multirow{2}{*}{$\begin{array}{l}\text { Nomor } \\
\text { sudu } \\
\text { difuser }\end{array}$} & \multicolumn{3}{|c|}{$\begin{array}{l}\text { Laju aliran massa udara difuser jet } \\
\text { swirling sudut sudu } 60^{\circ} \text { terhadap } \\
\text { sumbu } Z(\mathrm{~kg} / \mathrm{s})\end{array}$} \\
\hline & & & $\dot{\mathbf{m}}_{x}$ & $\dot{\mathrm{m}}_{\mathrm{y}}$ & $\dot{\mathrm{m}}_{\mathrm{z}}$ \\
\hline & & 1 & $\begin{array}{c}5,4819 \\
10^{-3} \\
\end{array}$ & 0 & $\begin{array}{c}-3,165 . \\
10^{-3}\end{array}$ \\
\hline & & 2 & $\begin{array}{c}5,2135 \\
10^{-3}\end{array}$ & $\begin{array}{c}-1,6940 \\
10^{-3} \\
\end{array}$ & $\begin{array}{c}-3,165 . \\
10^{-3}\end{array}$ \\
\hline & & 3 & $\begin{array}{c}4,4349 \\
10^{-3} \\
\end{array}$ & $\begin{array}{c}-3,2220 \\
10^{-3} \\
\end{array}$ & $\begin{array}{c}-3,165 . \\
10^{-3}\end{array}$ \\
\hline & & 4 & $\begin{array}{c}3,2220 \\
10^{-3}\end{array}$ & $\begin{array}{c}-4,4349 \\
10^{-3} \\
\end{array}$ & $\begin{array}{c}-3,165 . \\
10^{-3}\end{array}$ \\
\hline & & 5 & $\begin{array}{c}1,6940 \\
10^{-3} \\
\end{array}$ & $\begin{array}{c}-5,2135 \\
10^{-3} \\
\end{array}$ & $\begin{array}{c}-3,165 . \\
10^{-3} \\
\end{array}$ \\
\hline
\end{tabular}

\begin{tabular}{|c|c|c|c|c|c|}
\hline & & $\ldots(\mathrm{dst})$ & $\ldots$ & $\ldots$ & $\ldots$ \\
\cline { 3 - 6 } & & 20 & $\begin{array}{c}5,2135 . \\
10^{-3}\end{array}$ & $\begin{array}{c}1,6940 . \\
10^{-3}\end{array}$ & $\begin{array}{c}-3,165 . \\
10^{-3}\end{array}$ \\
\hline 6 & Outlet & $\begin{array}{c}\text { Pressure } \\
\text { outlet }\end{array}$ & \multicolumn{3}{|c|}{$101325\left(\mathrm{~N} / \mathrm{m}^{2}\right)$} \\
\hline
\end{tabular}

(c) Data Kondisi Operasi:

- Tekanan :

- Tekanan operasi $(\mathrm{Pa}) \quad=101325 \mathrm{~N} / \mathrm{m}^{2}$

- Referensi Pressure Location $=(0,0,0)$

- Gravity:

$$
\begin{aligned}
& -\mathrm{g}_{\mathrm{x}}\left(\mathrm{m} / \mathrm{s}^{2}\right) \quad=0 \\
& \text { - } \mathrm{g}_{\mathrm{y}}\left(\mathrm{m} / \mathrm{s}^{2}\right) \quad=0 \\
& -\mathrm{g}_{\mathrm{z}}\left(\mathrm{m} / \mathrm{s}^{2}\right) \quad=-9,81
\end{aligned}
$$

- Temperatur Operasi $\left({ }^{\circ} \mathrm{C}\right)=19$

\section{b) Data Simulasi Untuk Difuser "Grille" $A C$ Split}

Difuser "grille" AC Split yang disimulasikan dibedakan atas dua model, berdasarkan variasi sudut sudu pengarahnya yaitu $45^{\circ}$ dan $60^{\circ}$ terhadap sumbu Z.

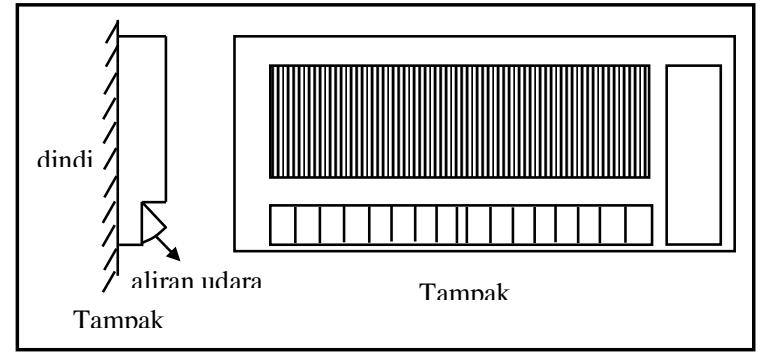

Gambar 10. Difuser "Grille” AC Split

Total laju aliran massa udara supply

$$
\begin{array}{lll} 
& =0,123217 \mathrm{~kg} / \mathrm{s} \\
\text { Jumlah sudu pada difuser catu } & =16 \\
\text { Temperatur udara catu } & =17^{\circ} \mathrm{C} \\
\text { Laju aliran massa udara tiap difuser } & \\
\text { catu } & =0,007701 \mathrm{~kg} / \mathrm{s}
\end{array}
$$

Data-data masukan untuk Fluent pada simulasi difuser jenis ini sama dengan data masukan untuk simulasi pada difuser jet swirling. Hal yang membedakan adalah kondisi batas masukan udara ke dalam ruangan, keluar dari difuser "grille" AC Split. Data kondisi batas masukan udara ke dalam ruangan untuk difuser "grille" AC Split dapat dilihat pada table 5 berikut ini : 
Tabel 5. Data Kondisi Batas Masukan Udara ke dalam Ruangan untuk Difuser "Grille” AC Split.

\begin{tabular}{|c|c|c|c|c|c|}
\hline No & Jenis & $\begin{array}{c}\text { Kondisi } \\
\text { Batas }\end{array}$ & \multicolumn{3}{|c|}{$\begin{array}{c}\text { Nilai Fluks Panas } \\
\left(\mathbf{W} / \mathbf{m}^{2}\right)\end{array}$} \\
\hline 1 & $\begin{array}{l}\text { Dinding } \\
\text { Utara, } \\
\text { Selatan, } \\
\text { Barat dan } \\
\text { Timur }\end{array}$ & Wall & \multicolumn{3}{|c|}{5,$597 ; 8,682 ; 4,715 ; 6.928$} \\
\hline 2 & Lantai & Wall & \multicolumn{3}{|c|}{8,480} \\
\hline 3 & Plafon & Wall & \multicolumn{3}{|c|}{7,928} \\
\hline \multirow[t]{2}{*}{4} & \multirow[t]{2}{*}{ Inlet } & \multirow{2}{*}{$\begin{array}{c}\text { Nomor } \\
\text { posisi } \\
\text { antara } \\
\text { sudu } \\
\text { pada } \\
\text { grille }\end{array}$} & \multicolumn{3}{|c|}{$\begin{array}{c}\text { Laju aliran massa udara } \\
\text { difuser "grille" AC Split } \\
\text { sudut sudu } 45^{\circ} \text { terhadap } \\
\text { sumbu } Z(\mathrm{~kg} / \mathrm{s})\end{array}$} \\
\hline & & & $\dot{\mathrm{m}}_{x}$ & $\dot{\mathrm{m}}_{\mathrm{y}}$ & $\dot{\mathrm{m}}_{\mathrm{z}}$ \\
\hline \multirow{3}{*}{5} & & 1 & 0 & $\begin{array}{c}-5,4455 \\
10^{-3}\end{array}$ & $\begin{array}{c}-5,4455 \\
10^{-3}\end{array}$ \\
\hline & & $\ldots(\mathrm{dst})$ & $\ldots$ & $\ldots$ & $\ldots$ \\
\hline & & 16 & 0 & $\begin{array}{c}-5,4455 \\
10^{-3}\end{array}$ & $\begin{array}{c}-5,4455 \\
10^{-3}\end{array}$ \\
\hline \multirow[t]{5}{*}{6} & \multirow[t]{2}{*}{ Inlet } & \multirow{2}{*}{$\begin{array}{c}\text { Nomor } \\
\text { posisi } \\
\text { antara } \\
\text { sudu pada } \\
\text { grille }\end{array}$} & \multicolumn{3}{|c|}{$\begin{array}{c}\text { Laju aliran massa udara difuser } \\
\text { "grille" AC Split sudut sudu } \mathbf{6 0}^{\circ} \\
\text { terhadap sumbu Z }(\mathrm{kg} / \mathrm{s})\end{array}$} \\
\hline & & & $\dot{\mathrm{m}}_{x}$ & $\dot{\mathrm{m}}_{\mathrm{y}}$ & $\dot{\mathrm{m}}_{\mathrm{z}}$ \\
\hline & & 1 & 0 & $\begin{array}{c}- \\
6,6693.1 \\
0^{-3}\end{array}$ & $\begin{array}{c}- \\
3,8505.10 \\
-3\end{array}$ \\
\hline & & $\ldots(\mathrm{dst})$ & $\ldots$ & $\ldots$ & $\ldots$ \\
\hline & & 16 & 0 & $\begin{array}{c}- \\
6,6693.1 \\
0^{-3}\end{array}$ & $\begin{array}{c}- \\
3,8505.10 \\
-3\end{array}$ \\
\hline
\end{tabular}

\section{HASIL DAN PEMBAHAAN}

Hasil pada penelitian ini merupakan hasil simulasi numerik menggunakan paket Program Computational Fluids Dyanamic Fluent 4.2.

\section{A. Distribusi Temperatur Udara Dalam Ruangan Terkondisi}

Distribusi temperatur dalam ruang terkondisi pada hakekatnya juga dipengaruhi oleh pola aliran udara yang dihasilkan oleh diffuser udara. Gambar 11 dan 12 memperlihatkan kontur distribusi temperatur udara dalam ruangan keluaran dari diffuser jet swirling sudut sudu $45^{\circ}$ dan $60^{\circ}$.

Pada gambar 11 terlihat, udara lebih menyebar secara merata ke semua titik dalam ruang. Hal ini terlihat dari warna kontor pada gambar 11, yang warna birunya lebih merata dan lebih tua (deep) dan sedikit warna kuningnya. Pada tepi-tepi ruang temperataur agak sedikit lebih tinggi dibanding di tengah-tenagh ruang. Dari data simulasi diperoleh bahwa capaian temperatur rata-rata untuk diffuser sudut sudu $45^{\circ}$ dalam ruang yang dikondisikan adalah $20,05^{\circ} \mathrm{C}$.

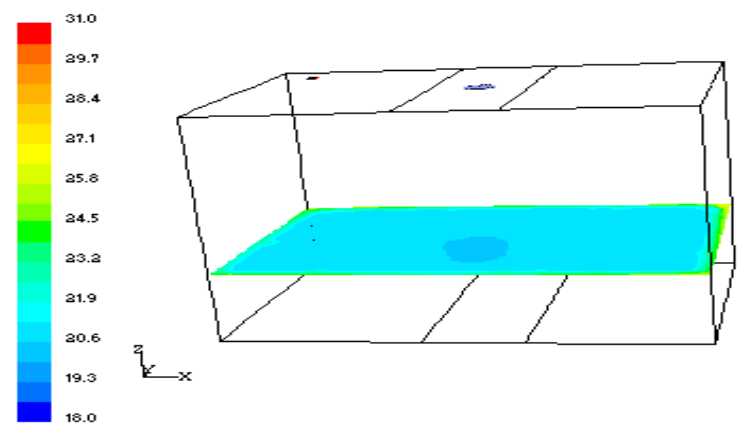

Gambar 11. Kontur Distrubusi Temperatur dalam Ruangan Keluaran Diffuser Jet Swirling SuduSudu $45^{\circ}$

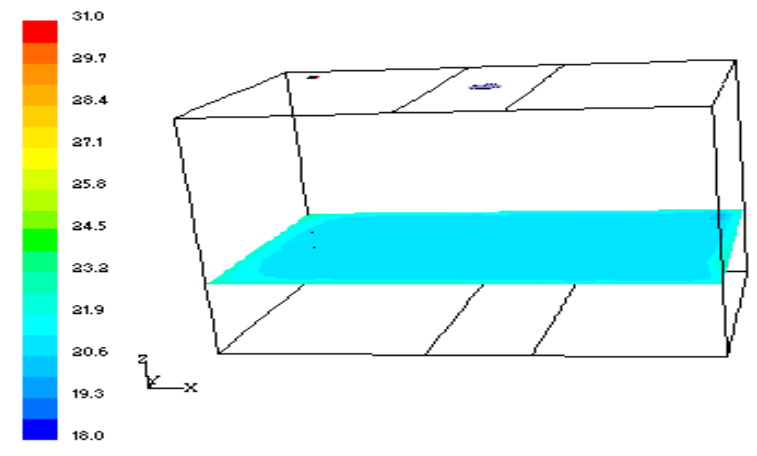

Gambar 12. Kontur Distribusi Temperatur dalam Ruangan Keluaran Diffuser Jet Swirling Sudut Sudu $60^{\circ}$

Distribusi temperatur oleh diffuser jet swirling sudut sudu 60 terlihat pada gambar 12. Dari gambar 12 penyebaran temperatur juga mera hamper kesemua ruang dengan kisaran 19,3 ${ }^{\circ}$ $20,6^{\circ}$. Jika dilihat dari kontur temperaturnya terlihat biru muda rata. Pada bagian tepi ruang lebih banyak warna kuningnya. Hal ini menunjukan bahwa temperatur di tepi ruang agak lebih tinggi jika dibandin dengan distribusi temperature oleh sudu sudu $45^{\circ}$. Rata-rata capaian temperatur hasil distribusi diffuser jet swirling sudut sudu $60^{\circ}$ adalah $20,97^{\circ} \mathrm{C}$. Terjadi perbedaan hampir $1^{\circ} \mathrm{C}$ antara sudut sudu $45^{\circ}$ dengan $60^{\circ}$. 


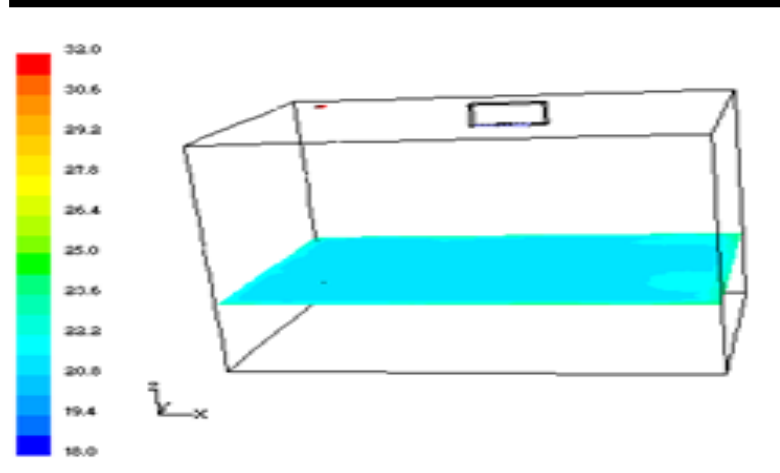

Gambar 13. Distrubusi Temperatur dalam Ruangan Diffuser Grille Sudut Sudu 45
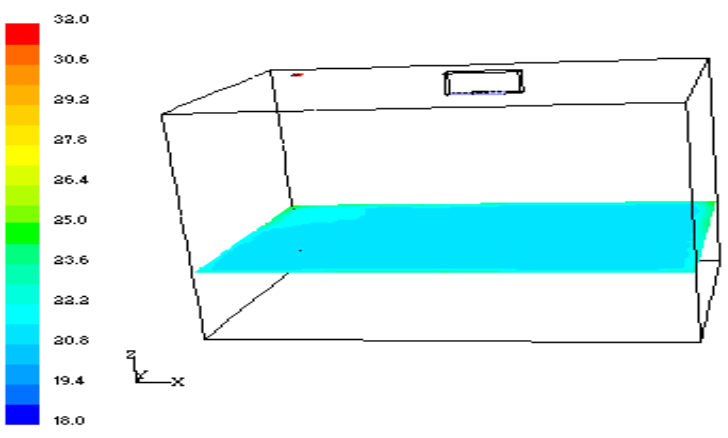

Gambar 14. Distrubusi Temperatur dalam Ruangan Diffuser Grille udut Sudu $60^{\circ}$

Gambar 13 adalah kontur distribusi temperatur dalam ruangan keluaran dari diffuser grille dengan sudut sudu $45^{\circ}$. Dari gambar 13 terlihat distribusi temperatur udara lebih banyak terlihat di sekitar tengah ruang, berwarna biru muda rata. Sedangkan untuk sudu sudu $60^{\circ}$ terlihat juga distribusi tempartur yang merata juga tetapi agak lebih muda jika disbanding dengan sudut sudu $45^{\circ}$. Capaian rata temperature ruangan pada susud sudu $45^{\circ}$ adalah $21,54^{\circ} \mathrm{C}$ dan sudut sudu 60 adalah $21,09^{\circ} \mathrm{C}$. Perbedaan capaian temperatur rata-rata terendah oleh sudut sudu $60^{\circ}$ adalah sekitar $0,5^{\circ} \mathrm{C}$.

Fenomena tersebut di atas jika dianalisa secara teoritis mungkin karena udara dingin banyak terkonsentrasi ditengah-tengah ruangan sehingga saat pengukuran rata-rata temperatur ruang di 9 titik tersebut relatif tinggi. Udara keluaran sudut sudu $45^{\circ}$ untuk diffuser grille lebih banyak terkonsentrasi di tengah-tengah ruangan, sehingga kurang menyebar. Hal ini dapat dilihat dari kontor temperature gambar 13. Pada gambar terlihat banyak tumpukan-tumpukan warna biru muda yang melambangkankan di titik tersebut temperature udara tinggi.

\section{B. Kecepatan Udara Dalam Ruangan Terkon-disi}

Kecepatan udara dalam ruangan yang dikondisikan didapatkan dari ketinggian 1 meter dari atas lantai. Untuk diffuser jet swirling sudut sudu $45^{\circ}$ dapat dilihat dari gambar 15. Pada gambar sangat jelas terlihat ada tumpukan udara di titik tengah ruang dari kontur berwarna kuning. Ratarata kecepatan udara keluaran diffuser jet swirling sudut sudu $45^{\circ}$ adalah $0,14 \mathrm{~m} / \mathrm{dt}$. Kecepatan udara yang dihasilkan sebesar 0,14 $\mathrm{m} / \mathrm{dt}$ sudah memenuhi kriteria nyaman kecepatan udara dalam ruang kerja.

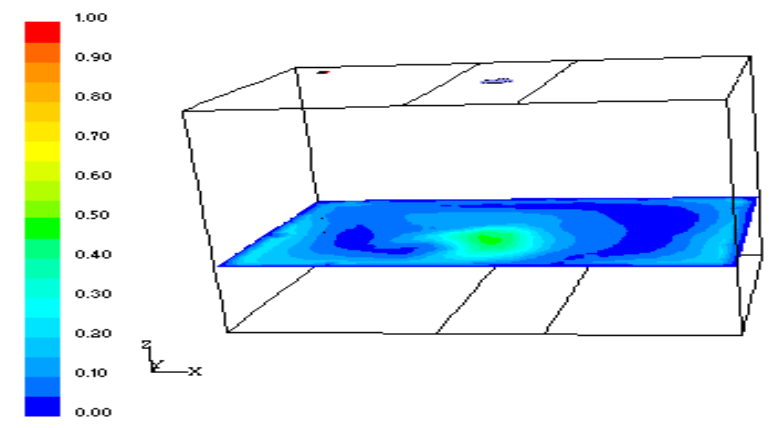

Gambar 15. Kecepatan Udara dalam Ruang Diffuser Jet Swirling Sudut Sudu $45^{\circ}$

Sedangkan untuk difuser jet swirling sudut sudu $60^{\circ}$ kecepatan udara yang bisa dicapainya adalah adalah $0,12 \mathrm{~m} / \mathrm{dt}$. Lebih rendah disbanding dengan diffuser jet swirling sudut sudu $45^{\circ}$. Pada kontur kecepatan udara gambar 16 terlihat warna kontur lebih biru tua rata ada sedikit warna biru muda. Dari warna kontur pada gambar 16 didapat kecepatan rata-rata udara keluaran diffuser jet swirling sudut sudu $60^{\circ}$ lebih rendah dibanding sudut sudu $45^{\circ}$.

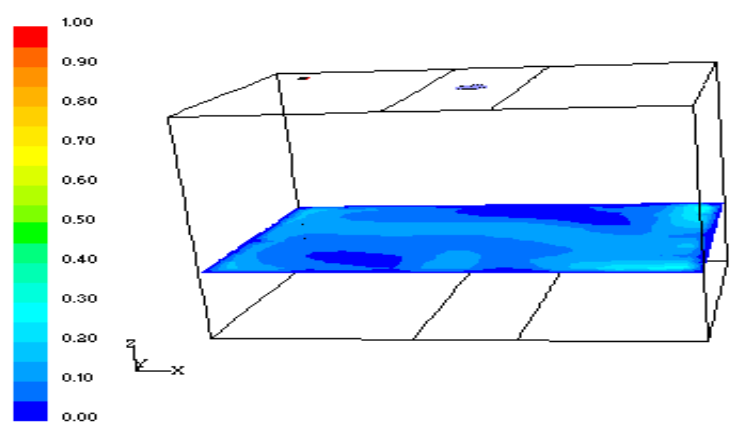

Gambar 16. Kecepatan Udara dalam Ruang Diffuser Jet Swirling Sudut Sudu $60^{\circ}$

Distribusi kecepetan udara keluaran dari disfuer grille sudut sudu $45^{\circ}$ dapat terlihat pada kontur kecepatan udara gambar 17. Pada gambar 
terlihat ada beberapa titik dalam ruangan dimana kecepatan udaranya cukup baik, Terlihat dari tumpukan warna kuning warna. Rata-rata capaian kecepatan udara dalam ruanag keluaran diffuser grille sudut sudu $45^{\circ}$ adalah $0,20 \mathrm{~m} / \mathrm{dt}$. Angka ini sangat memenuhi kriteria nyaman yang direkomendasikan.
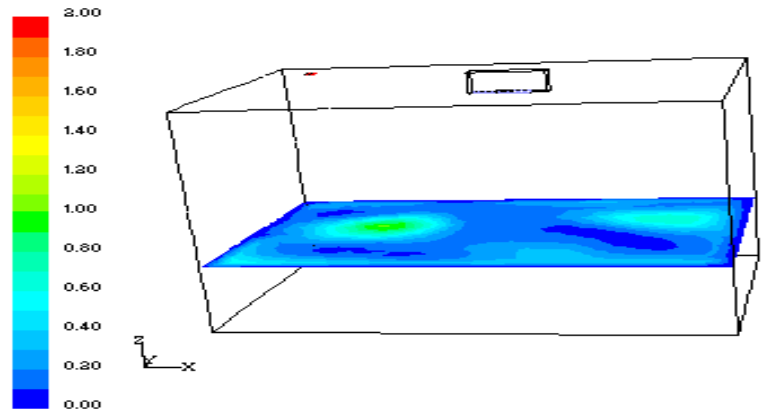

Gambar 17. Kecepatan Udara dalam Ruang Diffuser Grille Sudut Sudu 45

Capaian distribusi kecepatan udara keluaran difuser grille sudut sudu $60^{\circ}$ terlihat lebih merata diseluruh ruangan. Namun capaian kecepatan udaranya dibawah capaian kecepatan udara keluaran sudut sudu $45^{\circ}$ yakni sebesar $0,18 \mathrm{md} / \mathrm{t}$.
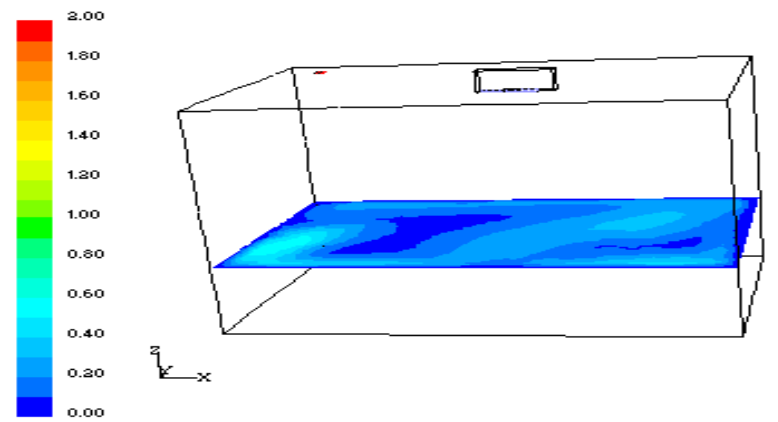

Gambar 18. Kecepatan Udara dalam Ruang iffuser Grille Sudut Sudu $60^{\circ}$

Untuk diffuser grille sudut sudu $60^{\circ}$ didapatkan rata -rata kecepetan udaranya adalah $0,20 \mathrm{~m} / \mathrm{dt}$. Hal ini dapat dari kontur kecepatan udara pada gambar 18. Dari kontur juga terlihat bahwa kecepatan udara lebih merata ke semua titik dalam ruangan jika dibanding diffuser grille sudut sudu $45^{\circ}$. Namun jika dirata-ratakan hasilnya kecepatan udara yang dicapai oleh sudut sudu $60^{\circ}$ sedikit di bawah sudut sudu $60^{\circ}$.

\section{Perbandingan Hasil Simulasi dengan Hasil Pengkuran}

Keakuratan hasil simulasi diperoleh jika dapat dibandingkan dengan hasil pengukuran secara eksperimen. Parameter yang dibandingkan adalah distribusi temperatur dan kecepatan udara pada ketinggian 1 meter dari atas lantai. Tabel 6 berikut adalah perbandingan hasil simulasi dengan hasil pengukuran secara eksperimen.

Tabel 6. Perbandingan Hasil Simulasi dan Pengukuran Distribusi Temperatur Udara Dalam

\begin{tabular}{|c|c|c|}
\hline \multirow{2}{*}{ Jenis Difuser } & \multicolumn{2}{|c|}{ Remperatur Udara $\left({ }^{\circ} \mathrm{C}\right)$} \\
\cline { 2 - 3 } & $\begin{array}{c}\text { Temperatur } \\
\text { Udara Hasil } \\
\text { Simulasi }\left({ }^{\circ} \mathrm{C}\right)\end{array}$ & $\begin{array}{c}\text { Temperatur } \\
\text { Udara Hasil } \\
\text { Pengukuran }\left({ }^{\circ} \mathrm{C}\right)\end{array}$ \\
\hline Jet Swirling $45^{\circ}$ & 20,0 & 20,23 \\
\hline Jet Swirling $60^{\circ}$ & 20,97 & 20,28 \\
\hline Grille $45^{\circ}$ & 21,54 & 20,2 \\
\hline Grille $60^{\circ}$ & 21,09 & 19,4 \\
\hline
\end{tabular}

Tabel 7. Perbandingan Hasil Simulasi dan Pengukuran Distribusi Kecepatan Udara Dalam Ruang

\begin{tabular}{|c|c|c|}
\hline \multirow{2}{*}{ Jenis Difuser } & \multicolumn{2}{|c|}{ Kecepatan Udara (m/dt) } \\
\cline { 2 - 3 } & $\begin{array}{c}\text { Kecepatan } \\
\text { Udara Hasil } \\
\text { Simulasi (m/dt) }\end{array}$ & $\begin{array}{c}\text { Kecepatan } \\
\text { Udara Hasil } \\
\text { Pengukuran } \\
\text { (m/dt) }\end{array}$ \\
\hline $\begin{array}{c}\text { Jet Swirling } \\
45^{\circ}\end{array}$ & 0,20 & $0,21^{*}$ \\
\hline $\begin{array}{c}\text { Jet Swirling } \\
60^{\circ}\end{array}$ & 0,18 & $0,18^{*}$ \\
\hline $\begin{array}{c}\text { Grille } 45^{\circ} \\
\text { Grille } 60^{\circ}\end{array}$ & 21,30 & $0,20^{* *}$ \\
\hline data dari tesis Ant & $0.18^{* *}$ \\
\hline
\end{tabular}

* data dari tesis Antonius Aji G. Wicaksono, Teknik Mesin ITB, 1993

**data dari tesis Arwizet K, Teknik Mesin, FTI ITB, 2003

\section{KESIMPULAN}

Kesimpulan yang dapat diambil dari hasil simulasi distribusi udara ke dalam ruangan oleh diffuser jet swirling dan grille adalah capaian temperatur terendah lebih cepat tercapai menggunakan diffuser sudut sudu $45^{\circ}$ untuk diffuset jet swirling, namun untuk difuser grille menggunakan sudut sudu $60^{\circ}$. Distribusi kecepatan udara menggunakan diffuser grille dengan sudu sudu $60^{\circ}$ lebih merata disetiap titik dalam ruang, namun nilainya lebih kecil dengan diffuser sudut sudu $45^{\circ}$. Akurasi hasil simulasi distribusi temperatur dan kecepatan udara dalam 
ruang mendekati hasil pengukuran secara eksperimen. Artinya simulasi ini dapat digunakan sebagai pengujian pada sistem distribusi udara.

\section{DAFTAR PUSTAKa}

[1] J. Sarsetiyanto and D. M. Soedjono, "Pengaruh Posisi Difuser dan Variasi Kecepatan Udara Masuk terhadap Distribusi Temperatur Ruang Terkondisi Sebuah Studi Numerik," J. Tek. Mesin, vol. 8, no. 1, pp. 17, 2006.

[2] W. F. Stocker and W. C. Jerold, Air Conditioning and Refrigeration. Mc-Graw Hill, New York, 1978.

[3] A. Badarudin, A. Setyawan, S. Sugiyarto, and U. N. Adilah, "OBSERVASI POLA ALIRAN UDARA DAN DISTRIBUSI TEMPERATUR PADA RUANG TERKONDISI MENGGUNAKAN CFD," EDUSAINTEK, vol. 3, 2019.

[4] S. A. Safitri, "Desain dan Analisis Sistem Pengkondisian Udara Berbasis Computational Fluid Dynamics (CFD) pada Kereta Ukur Sulawesi di PT. INKA (Persero)," PhD Thesis, Institut Teknologi Sepuluh Nopember, 2017.

[5] A. Handbook, "ASHRAE handbookfundamentals," Atlanta GA, 2009.

[6] R. Azzamudin and S. T. Marwan Effendy, "Analisis Distribusi Aliran Udara Pada Ruangan Dengan Variabel Temperatur dan Penempatan AC Menggunakan Metode Computational Fluid Dynamics (CFD)," PhD Thesis, Universitas Muhammadiyah Surakarta, 2017.

[7] C. Putri and C. Radios, "Studi Numerik Aliran Fluida Melewati Diffuser Dengan Variasi Bentuk Dan Bilangan Reynolds Untuk Aplikasi Inlet Duct HRSG," PhD Thesis, Institut Teknology Sepuluh Nopember, 2015.

[8] A. I. Bosioc, C. Tanasa, S. Muntean, and R. Susan-Resiga, "Pressure recovery improvement in a conical diffuser with swirling flow using water jet injection," Proc. Romanian Acad. Ser. Math. Phys. Tech. Sci. Inf. Sci. ISSN, vol. 14549069, 2010.

[9] V. M. Domkundwar, V. Sriramulu, and M. C. Gupta, "Analysis of swirling recirculating reacting turbulent jets passing through diffusers," Combust. Flame, vol. 33, pp. 241249, 1978.

[10]R. Faiz, "ANALISIS POLA ALIRAN MENGGUNAKAN ANSYS FLUENT," PhD Thesis, Fakultas Teknik Unpas, 2019.

[11] A. Ramadhani, "Pengaruh Sudut Swirl Vanes Terhadap Visualisasi Dan Distribusi Temperatur Api Difusi," PhD Thesis, Universitas Brawijaya, 2016.
[12] W. Priatna and A. B. KP, "Perencanaan Ulang Sistem Pengkondisian Udara Pada lantai 1 dan 2 Gedung Surabaya Suite Hotel Di Surabaya," J. Tek. ITS, vol. 5, no. 2, pp. A634-A639, 2016.

[13]D. ME Soedjono, "Kaji numerik dan eksperimental distribusi temperatur pada ruangan dengan variasi kecepatan udara masuk difuser dan posisi difuser.," 2000.

[14] V. M. Molochnikov, N. I. Mikheev, and O. A. Dushina, "Simulation of subsonic flows with separation using the FLUENT program package: software applicability study," Thermophys. Aeromechanics, vol. 16, no. 3, p. $367,2009$.

[15]A. Mulyana, "PERBANDINGAN PEMODELAN NUMERIKMENGGUNAKAN MODEL TURBULEN ENERGI KINETIK-DISIPASI (kg) DAN TEGANGAN REYNOLD (RSM) PADA TABRAKAN DUA JET SALING BERHADAPAN," J. Sains Dan Teknol. Indones. Ed. Energi Dan Aspeknya BPPT, 2000.

[16] A. A. Azis and S. T. Marwan Effendy, "Prediksi Karakteristik Temperatur dan Kecepatan Udara Pada Ruangan Berpendingin AC dengan Metode Pendekatan Computational Fluid Dynamics (CFD), " PhD Thesis, Universitas Muhammadiyah Surakarta, 2018.

[17]H. Rachman and B. Widodo, "MODEL NUMERIK DISTRIBUSI TEMPERATUR PADA RUANG BER-AC DENGAN MEMPERTIMBANGKAN INTERNAL DRAG."

\section{Biodata Penulis}

Arwizet Karudin lahir di Pariaman, 20 September 1969. Sarjana Teknik (S1) di Jurusan Teknik Mesin, Fakultas Teknik Universitas Andalas 1995. Tahun 2003 memperoleh gelas Magister Teknik (S2) dari Jurusan Teknik Mesin FTI ITB Bandung dalam bidang Mesin Konversi Energi. Program Doktor (S3) diperoleh dari Pascasarjana Pendidikan Teknologi dan Kejuruan Fakultas Teknik Universitas Negeri Padang 2017. Staf pengajar di Jurusan Teknik Mesin, FT. UNP Padang sejak 1998-sekarang. 
